\title{
A Decade of Experience of Examining Candidates for Entry to the Army
}

\author{
Maj Gen (Retd) A P Dignan
}

MA, MD, FRCS, L/RAMC

\section{Formerly President, Standing Medical Boards, London District}

SUMMARY: A total of 3886 civilian candidates were medically examined for entry to the Army during the period $198 \Phi$ to 1990 .

Eight per cent of the candidates failed their examination. The commonest causes for rejection were back and knee disorders, the majority associated with trauma. The next most common disorder was hearing loss, closely followed by myopia.

Analysis of the incidence of individual conditions showed that only hearing loss and myopia were more prevalent than spondylolisthesis. It is felt, therefore, that consideration should be given to the routine radiographic screening of al candidates for spondylolisthesis and indeed for spondylolysis.

The incidence of medical conditions was low.

In the assessment of the individual's fitness for entry, the effects of military training and service in the field on his on her functional capacity must be considered.

Problems that may arise when a candidate is rejected are discussed.

\section{Introduction}

This report deals with the experience of a President of Standing Medical Boards (PSMB) examining candidates for entry to the Army over a period of 10 years, $1980-$ 1990.

\section{Material and Methods}

The total number of candidates examined was 3886 . The candidates consisted of 2944 for entry to RMAS including 290 applicants for Army Scholarships and entry to Welbeck College who were considered to be potential candidates for entry to the Army in due course, and 942 for direct commissioning in a non combatant corps. The standard of fitness required for entry was basically the same for all candidates.

Fitness for Service was based upon the PULHEEMS system of medical grading as laid down in the PULHEEMS Administrative Pamphlet (1), in conjunction with the instructions contained in JSP 346 (2).

\section{Results}

Of the 3886 candidates examin $d$ by medical boards, $310(8 \%)$ were found to be unfit for entry.

Twenty-one candidates presented with two or more conditions causing rejection.

When the reasons for rejection were examined, it was found that there were seven main groups of conditions (Table 1) presenting in the candidates who failed, with, in addition, a miscellaneous group.

In the following analysis of the results, it is to be noted that all percentages recorded are percentages of the total number of the candidates rejected.

It can be seen from Table 1 that the orthopaedic group with 107 cases $(34.5 \%)$, produced the highest number of failures. This was followed by the aural -57 cases $(18.4 \%)$; ophthalmic - 42 cases $(13.5 \%)$; pulmonary -
Table 1

Incidence of the Groups of Conditions in Failed Candidates

\begin{tabular}{|c|c|c|}
\hline Main Groups & Number of Cases & 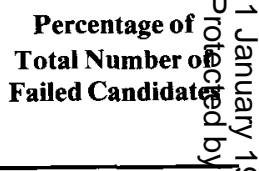 \\
\hline (1) Orthopaedic & 107 & 34.5 \\
\hline (2) Aural & 57 & 18.4 \\
\hline (3) Ophthalmic & 42 & 13.5 \\
\hline (4) Pulmonary & 24 & 7.7 \\
\hline (5) Dermatological & 23 & 7.4 \\
\hline (6) Neurological & 13 & 4.2 \\
\hline (7) Genito-Urinary & 12 & 3.84 \\
\hline
\end{tabular}

24 cases $(7.7 \%)$; dermatological -23 cases $(7.4 \%)$ neurological -13 cases $(4.2 \%)$; and genito-urinary $\overrightarrow{0}$ 12 cases $(3.8 \%)$.

When the aetiology of the orthopaedic group of con ditions was considered, it was found that $74(69.1 \%)$ o the cases were associated with trauma (Table 2 ).

Table 3 lists the incidence of the common individua conditions that presented. In the order of frequenc

Table 2

Orthopaedic Conditions Associated with Trauma

\begin{tabular}{|c|c|c|}
\hline Condition & Number of Cases & 으 \\
\hline $\begin{array}{l}\text { Back } \\
\text { Knee } \\
\text { Neck } \\
\text { Limb }\end{array}$ & $\begin{array}{r}33 \\
32 \\
3 \\
6\end{array}$ & $\begin{array}{l}\frac{D}{0} \\
\text { O } \\
\text { N }\end{array}$ \\
\hline Total & 74 & స్లు \\
\hline
\end{tabular}


Table 3

Individual Conditions that Presented in the Failed Candidates

\begin{tabular}{lll}
\hline Condition & $\begin{array}{l}\text { Number of } \\
\text { Cases }\end{array}$ & $\begin{array}{l}\text { Percentage of Total } \\
\text { Number of Failed } \\
\text { Candidates }\end{array}$ \\
\hline (1) Disorders of Back & & \\
and Knee & 85 & 27.4 \\
(2) Hearing Loss & 38 & 12.2 \\
(3) Myopia & 33 & 10.6 \\
(4) Asthma & 20 & 6.4 \\
(5) Ear Infection & 19 & 6.1 \\
(6) Eczema & 12 & 3.9 \\
\hline
\end{tabular}

these conditions consisted of back and knee disorders 85 cases $(27.4 \%)$; hearing loss - 38 cases $(12.2 \%)$; myopia -33 cases $(10.6 \%)$; asthma -20 cases $(6.4 \%)$; ear infection -19 cases $(6.1 \%)$ and eczema - 12 cases $(3.9 \%)$.

When the disorders of the back and knee were analysed (Table 4), it was found that there were 3 main conditions presenting as a cause for rejection, i.e. spondylolisthesis - 27 cases $(8.7 \%)$; knee ligament weakness - 12 cases $(3.9 \%)$; and chondromalacia patella - 10 cases $(3.2 \%)$.

The number of cases in the neurological and genitourinary groups was small and they are recorded in Tables 5 and 6 respectively.

The miscellaneous group consisted of disparate conditions of insignificant numbers (Table 7).

Eighty-nine $(2.5 \%)$ of the candidates failed the 'Homes-Wright Lantern' colour perception test (CP 4). Those who were examined for a commission in a non combatant corps and were otherwise fit were recommended for acceptance. The remaining candidates, who failed the test but were otherwise fit, were recommended for acceptance at the discretion of the Director of Army Recruiting, in accordance with the instructions given in the PULHEEMS Administrative Pamphlet. The candidates who failed the test are not included in the total number of candidates who failed their medical examination for entry.

\section{Discussion}

Eight per cent, a ratio of 1 in 12.5 , of the candidates failed their medical examination.

In a search of the literature, no study was found that could be used to compare with the author's experience. However, Sinclair (3), in a study of 208 potential recruits examined on entry, recorded a $19 \%$ medical failure rate.

The findings of the orthopaedic group of conditions presenting in the largest number of failed candidates, could be expected in view of the relative youth of the majority of subjects examined in this study, bearing in mind that sixty-nine per cent of the latter conditions were associated with trauma.

Disorders of the back and knee joint, together were the commonest cause of failure of candidates, and of these disorders, spondylolisthesis $(31.7 \%)$ was the most prevalent.
Tabie 4

Conditions that Presented in Disorders of the Back and Knee

\begin{tabular}{lll}
\hline Condition & $\begin{array}{l}\text { Number of } \\
\text { Cases }\end{array}$ & $\begin{array}{l}\text { Perce } \\
\text { Num } \\
\text { Candin }\end{array}$ \\
\hline Spondylolisthesis & 27 & 8.7 \\
$\begin{array}{l}\text { Knee Ligament Weak- } \\
\text { ness }\end{array}$ & 12 & 3.9 \\
Chondromalacia Patella & 10 & 3.2 \\
\hline
\end{tabular}

Table 5

Neurological Group of Conditions

\begin{tabular}{|c|c|c|}
\hline Condition & $\begin{array}{l}\text { Number of } \\
\text { Cases }\end{array}$ & $\begin{array}{l}\text { Percentage of Total } \\
\text { Number of Failed } \\
\text { Candidates }\end{array}$ \\
\hline $\begin{array}{l}\text { Migraine } \\
\text { Epilepsy } \\
\text { Dyslexia }\end{array}$ & $\begin{array}{l}9 \\
3 \\
1\end{array}$ & $\begin{array}{l}2.9 \\
.96 \\
.32\end{array}$ \\
\hline Total & 13 & 4.18 \\
\hline
\end{tabular}

Table 6

Genito-Urinary Group of Condition

\begin{tabular}{|c|c|c|}
\hline Condition & $\begin{array}{l}\text { Number of } \\
\text { Cases }\end{array}$ & $\begin{array}{l}\text { Percentage of Total } \\
\text { Number of Failed } \\
\text { Candidates }\end{array}$ \\
\hline $\begin{array}{l}\text { Urinary Tract Infection } \\
\text { Ectopia Testis } \\
\text { Reflux Nephropathy } \\
\text { Congenital } \\
\text { Hydronephrosis } \\
\text { Teratoma of Testis } \\
\text { Haematuria- } \\
\text { Undiagnosed }\end{array}$ & $\begin{array}{l}5 \\
3 \\
1 \\
1 \\
1 \\
1 \\
1\end{array}$ & $\begin{array}{l}1.6 \\
.96 \\
.32 \\
.32 \\
.32 \\
.32\end{array}$ \\
\hline Total & 12 & 3.84 \\
\hline
\end{tabular}

Table 7

Miscellaneous Group of Conditions

Condition Number of Cases

Cardiovascular

Haematological

Gastrointestinal

Gynaecological

Neoplastic

Psychiatric

Diabetes Mellitus

Thyroid Gland

Obesity

Scleroderma

Pilonidal Sinus

Hay Fever

Frostbite 
The next highest incidence of conditions presenting in failed candidates were defective hearing and vision and they were followed by asthma and ear infections, the only other conditions that it could be said had any significant incidence.

When the incidence of spondylolisthesis is compared with the incidence of other conditions, it is found that only hearing loss and myopia were more prevalent.

Bonnici, Koka and Richards (4) recently stated that the separation in the pars is always due to a fatigue fracture. In their series of 24 cases of spondylolisthesis, they found 11 cases presented with pain of acute onset following injury to the back during the teens and early twenties. They felt that it was reasonable to assume that that was the time their stress fractures occurred but, however, it also was possible that the onset of their back pain was related to an acute back strain superimposed on an already present spondylolisthesis. They found only one isolated documented case of spontaneous healing of a pars fracture in the literature.

In the present study, the use of a finger to detect a palpable 'step' in the lumbo-sacral spine was responsible for the finding of a 'pars defect' with evidence of a 'slip' when X-ray examination was subsequently carried out. Invariably, the candidate was symptomless and gave no history of back injury. However, in most cases, when informed of the finding, the candidate would recall an episode of back pain usually when playing games in late adolescence.

Among medical conditions, only asthma presented as an important illness. Fleming and Crombie (5) recently commented on asthma's increasing prevalence and more frequent recognition in children. Carson (6) in his personal view on bronchial asthma in servicemen stated that adults with even mild symptomatic asthma do not do well in service life. The JSP states that candidates who have had symptoms in the previous four years should be rejected. Those candidates who had been symptom free in the latter period were referred for exercise vitalography and if found to have abnormal bronchial lability were rejected.

The one case of hay fever rejected suffered from severe symptoms including wheezing and needed to take medication to control them.

The reason for rejecting the nine cases of migraine was that they had a long history of significant symptoms and to gain relief from them they had to take medication and rest during an attack.

In Table 8, a list of some of the conditions of unusual interest, which presented in the candidates rejected, is recorded. An appraisal of the list emphasises the importance and necessity of taking a careful and exact medical history and of undertaking a meticulous and detailed physical examination.

There were some conditions, that frequently presented on clinical examination, which were not of sufficient severity to warrant rejection of a candidate. Chest
Table 8

\section{Some Conditions of Unusual Interest that Presented}

Orthopaedic

Short leg, slipped femoral epiphysis, old Perthes disease of hipg sacro-ilietis, and habitual subluxation of shoulder and sterno clavicular joints.

Chest

Pulmonary sarcoidosis and tuberculosis.

Cardiovascular

Hypertrophic obstructive cardiomyopathy and symptomati mitral valve leaflet prolapse.

Haematological

Haemophilia and thrombocytosis.

Renal

Reflux nephropathy, and congenital hydronephrosis.

Thyroid Gland

Solitary thyroid nodules (including papillary thyroid carcinoma).

Neoplastic
Thyroid gland papillary carcinoma, teratoma of testis and lymphoma.

Connective Tissue Disease

Scleroderma.

Dermatological

Cold urticaria and vitiligo.

Ophthalmic

Keratoconnus, central scotoma, and cataract.

Gastro-Intestinal

Hiatus hernia. Crohn's disease and imperforate anus surgery.

asymmetry and postural scoliosis were common fir ings, and were often associated with the candidate hgve ing been an oarsman at school.

Congenital short leg of a minimum degree (less tt $1.5 \mathrm{~cm}$ ) was not an unusual finding. A common phys finding in a hip of a candidate who was asymptomatio with no history of joint disorder, was a reduced amouno of internal rotation associated with an excessive range on external rotation and normal radiological findings $\vec{\circ}$ Hyperextension mobility of digits with sometimes simi lar mobility of the elbows and knees was a common finding also.

In his assessment of the candidate's fitness for service the PSMB must be clear and concise in his thinking anf use sound commonsense. Although, bearing in mind that it is the functional capacity and motivation of the individual that matters most, the PSMB must at the same time give thought to the possibility of any deterioration in the future. He should envisage, for example, what the consequences might be if the individual were to becomes unfit on active service.

In addition, apart from taking into account the inter est of the Service and indeed the interests of the individual, due regard must be given to the financial im plications of an individual being medically dischargef during basic training.

In recent years, there has been increasing public dọ mand for open access to personal medical information and increasing understanding by the public of medicaf 
terminology and conditions. There has also been a dramatic increase in the frequency of negligence claims against doctors. As a result, a PSMB has to give a great deal more thought and care to the way he conducts the medical board proceedings and specifically to how he communicates with the candidate.

Finally, the decision of a medical board to recommend the rejection of a candidate may evoke a reaction from his or her parents, and indeed from persons in high office in civilian life. The parents' reaction usually takes the form of consulting their GP and/or a civilian specialist. The civilian specialist may lack knowledge of the standards of fitness required for military service or indeed specifically of the effects the stresses of military training may have on a particular condition. As a result, the parents may be misguided and in due course appeal against the medical board's recommendation. Interviewing the parents of a candidate at an early stage after the completion of the medical board was considered by the PSMB to be the most appropriate way of preventing problems arising from the rejection of a candidate.

\section{Conclusions}

The finding of a high incidence of disorders of the back and knee, the majority of which were associated with trauma and of the low incidence of medical conditions, can be understood when it is borne in mind that the subjects examined were healthy young adults who had spent a good deal of their life playing games at school.

On the other hand, the high incidence of aural and ophthalmic disorders is surprising and requires explanation.

The prevalence of spondylolisthesis amongst the conditions causing rejection needs consideration from the point of view of deciding whether or not, all candidates should have a routine X-ray examination to exclude its presence or indeed that of spondylolysis.

The functional capacity of an individual must be assessed on a long term and not on a short term basis. Careful and exact medical history taking, meticulous and detailed physical examination and skill in the art of communication are of the utmost importance in the medical examination of a candidate.

Finally, to prevent problems arising when a candidate $\stackrel{\Omega}{\alpha}^{\infty}$ is rejected, interviewing the parents should be a routine procedure.

\section{Acknowledgements}

The contributions made to my Medical Boards by its members, the late Major General J McGhie and Brigadier T P McKelvey in the past, and Colonel V Noone in $\frac{\bar{c}}{\bar{c}}$ recent years, is acknowledged and appreciated. I also $\widetilde{\widetilde{\Phi}}$ have to thank Brigadier McKelvey for my indoctrination 0 in the workings of a Medical Board.

The work done by Mrs J Watmore, Secretary to $\overrightarrow{0}$ London District Standing Medical Boards, Mrs B Willis, Secretary to the QEMH Medical Boards, Mrs H Taylor, $\vec{\omega}$ audio-typist and their predecessors is also acknow? ledged. I also have much appreciated the expert guidance given to the Medical Boards over the years by the Specialists on the staff of the QEMH.

Finally I am grateful to Major General M Brown foro his most helpful advice and comments.

Editor's note: JSP 346 has been extensively revisedo and will be re-issued in 1992 .

\section{REFERENCES}

1. Pulheems Administrative Pamphlet 1972 Arring Code No 13371.

2. Joint Service Publication 346. Pulheems. A Joimt Service System of Classification 1976 (Revisean) Ministry of Defence 1986.

3. Sinclair D M. The Enlistment Medical Examis tion - Reasons For Failure. J R Army Med Corps 1987; 133: 41-42.

4. Bonnici A V, Koka S R, Richards D J. Result of Buck Screw Fixation in Grade I Spondylolisthesis. $\mathscr{R}$ R Soc Med 1991; 84: 270.

5. Fleming D, Crombie D L. Prevalence of Asthma and Hay Fever in England and Wales. $\mathrm{Br}$ Med $J 1987$ 294: 279-283.

6. CARson J. Bronchial Asthma in Servicemen - A Personal View. J $R$ Army Med Corps 1988; 134: 138-145. 